\title{
Temporal Interpretation of Tense in Reported Speech
}

\author{
Shen Lei \\ Nanjing Xiaozhuang University \\ Nanjing, China \\ swanwheel@163.com
}

\begin{abstract}
This paper focuses on temporal interpretation of tense in reported speech with examples of past reporting clauses in English news texts. Tense in English expresses a relation between Speech Time, Reference Time and Situation Time. It is one of the important linguistic devices that contribute to temporal location. The information of temporal interpretation is conveyed by analyzing features of tense use from context-based point of view. And analysis shows that tense in reported speech in English news texts conveys a distinguished feature of being context-based.
\end{abstract}

\section{Keywords-temporal interpretation; tense; reported} speech;context

\section{INTRODUCTION}

Tense in reported speech is an area which remains curiously problematic in linguistic domain. On the grammatical side, "backshift" is seriously considered from direct speech John said "Mary is ill" to indirect speech John said Mary was ill [1]. Reported speech has been described from perspectives of structural linguistics with particular focus on syntactical operations for transforming direct speech into indirect speech as it is exampled above. The communicative functions of indirect and direct speech and their mutual relationship are discussed from functional grammatical approach. In contrast with the traditionally narrow focus on these phenomena, the information of tense interpretation depending on discourse context by interpretive rules is conveyed by features by syntactic configuration and by discourse context [2]. Fludernik relates tense to differences of narrative perspective and focalization with theories of narratology [3]. What seems to be missing is a linguistic approach with context base to analysis of tense in reported speech in news texts. We have known that the interpretation of tense requires information from context at least with its anaphoric nature. In sentences and passages, the meaning of every grammatically well-formed temporal expression is determined by tense in the syntactic context and the mode of the discourse.

In this paper we set out to develop such a general approach, which elucidates temporal interpretation of tense in reported speech with example sentences extracted from a corpus.

\section{TIME, TENSE AND REPORTED SPEECH}

Like space, time has an orientation point or landmark for location. The speaker is regarded as the canonical center of linguistic communication: the basic temporal orientation point is the speaker's time. Carlota takes "tense" to be a morpheme, either an inflection or auxiliary, which appears in the main verb phrase of a sentence and has a temporal meaning. Each tense assigns a temporal location to the situation talked about in its clause [2]. These words are partially true when they are used for explanation of current speech from the surface structure. The situation of reported speech is quite complicated and the theory of one single temporal reference point defined by the original speech act is not scant evidence to support the explanation of tense use in reported speech.

Reporting frame is the combination of devices used to set reported speech from current speech. The trunk of the form "speaker+ a reporting verb" determines the boundary between reporting and reported speech. A shift from reporting to reported speech causes changes in phonetic clues, syntactic attributes and semantic accounting. In the broad sense, reported speech constitutes direct speech and indirect speech. In the narrow sense, it refers to indirect speech, also called indirect discourse, which is a means of expressing the content of statements, questions or other utterances, without quoting them explicitly as is done in direct speech.

Some linguists hold that direct speech involves two deictic centres. Langacker points it out that direct speech, like all utteranhences, related to the speech event, or "ground" [4], which is constituted by the exchange between speaker, hearer and the temporal reference point defined by this exchange. At the same time, direct speech also involves a second "surrogate" ground with its own temporal coordinates. By contrast, indirect speech is generally assumed to have only one deictic centre, that of the actural speaker. All deictic elements of reported speech are claimed to be shifted towards this centre, including tense. It is believed that the represented speaker's deictic centre is crucial to a correct understanding of the domain constituted by topic, speaker's illocutions, proposition and other contextual clues, which impacts on the interpretation of the tense use in it.

\section{TEMPORAL INTERPRETATION OF TENSE}

\section{A. Reporting Verbs and Three Times}

Reporting verbs refers to verbs that describe or report an activity or action which has already taken place. They are associated with specific prepositions or are used with the 
relative pronoun that. The frequently used reporting verbs, such as claim, warn, demand, allege, accuse, deny, swear, confirm and testify, are always used in a past form in reported speech in news texts. The verbs in reporting are of special importance to the understanding and effect of speech communication. The neutral reporting verb-say is in common employment for research on reported speech.

To get a first empirically-based idea of tense use in reported speech in English news texts, we analyze and quantify the sample of sentences extracted from The Corpus of Contemporary American English (COCA). COCA is the largest freely-available corpus of English and the only large and balanced corpus of American English. We take said (that) as the search string. The search is executed through sub-corpora of newspaper in 2012. Then tense patterns of tokens of direct speech and indirect speech in news texts analyzed from the perspective of temporal interpretation.

We take accounts for temporal perspective by implicating it directly in temporal location. Following Reichenbach's theory as linguists usually do, we assume that a tense in a sentence involves three times: Speech Time (SpT), Reference Time (RT) and Situation Time (SitT) [5]. Speech Time is the orientation time of a sentence. Reference Time (RT) represents the temporal perspective of a sentence. It is simultaneous with, before, or after Speech Time (SpT). Situation Time (SitT) is the time of occurrence of a situation. It is simultaneous with, before, or after Reference Time (RT).

Following Kamp and Rohrer, we state the semantic meaning of a tense formally with two semantic features. Semantic A relates Reference Time to Speech Time. Semantic B relates Situation Time to Reference Time. The features provide a two-dimensional theory of tense [6].Within a sentence tense interacts with other temporal expressions to establish a time for temporal interpretation. What we are going to focus is on tense individually. One goal of the analysis is to illustrate what temporal information is conveyed by tense. Examples extracted from COCA are analyzed by using symbols- being simultaneous $(=)$, being prior $(<)$ and being after $(>)$ to indicate the temporal relations in terms of features.

\section{B. Tense in direct speech}

The dualism is an obvious feature of deictic centre in direct speech. There is a "deictic shift" from the actual speaker's to the represented speaker's deictic centre when utterances happen. The consequence of this shift is that tenses are plotted by the two distinct temporal domains of the reporting and the reported clause.

This claim can be best shown in examples in which the situation in the reported utterance is simultaneous with the act of speaking described by the matrix clause.

\section{1) Example 1}

Israeli Cabinet Minister Dan Meridor, whose responsibilities include monitoring the Iranian nuclear program, said there was broad agreement with the Americans and the West on the need to stop the Iranians. "If the sanctions work, then all the other options will remain strictly theoretical," he said. An air raid on Iran would require flying over potentially hostile Arab airspace and could well trigger a response from Iran, which possesses an arsenal of missiles capable of striking Israel...

(Source information: DOMESTIC NEWS, "US military chief in Israel to discuss Iran nukes" by JOSEF FEDERMAN and DAN PERRY, Associated Press in 2012)

The described speech act (said) is situated earlier in time than the situation of the reported utterance (If the sanctions work), which is located in the present time zone. "then all the other options will remain strictly theoretical" is true even it is located in the represented speaker's past intensional domain. The represented speech acts create what Rigter has called "intensional domains" in this discourse. This domains constitude their "own set of presuppositions and truth conditions" in terms of which propositions can be evaluated and interpreted [7].

Semantic A Semantic B

Time Line: $\mathrm{SpT}$ (he said) <RT (work, will remain) $\mathrm{RT}=$ SitT

Tense triggers the introduction of three times here into semantic representations. The tense in this example shifts from the actual speaker's domain to the domain of reported situation. As Haberland has proposed, "in order to refer to actions, states, etc. occurring or obtaining at the speakingtime of the model [the represented utterance]. They[speakers]" employ the tense to refer to actions and states occurring or obtaining at the point-of time of speaking[8]". This is named by Halliday as the "speaknow" [9] of the reported utterance.

\section{2) Example 2}

Kandahar provincial governor, said two children were among the seven civilians killed. He said eight other civilians, including two children and one woman, were injured in the explosion. Gates to the larger U.S. bases in Afghanistan often are crowded with trucks waiting to deliver goods and services, and local Afghans going to or coming back from jobs on the compounds. Safiullah, a 40year-old fuel tank driver from neighboring Zabul province, was waiting his turn to enter the base when the blast occurred. "There was dust and smoke everywhere, "said Safiullah, who uses just one name. "I got down on my knees. When the smoke lifted, I moved closer. I saw two children dead at the side of the road. " At the time of the explosion, two pickup trucks were leaving the base, he said...

(Source information: INTERNATIONAL NEWS, "6 NATO troops die in Afghanistan helicopter crash" by MIRWAIS KHAN, Associated Press, 2012)

The relation of anteriority between "there was, got, lifted, moved, saw" and "said" in this sentence is situated. The reported situation of the utterance is earlier than the speech act. Most striking use of present tense (who uses just one name) in this sentence shows that there is the current reporter's temporal location in this sentence.

Semantic A Semantic B SitT

Time Line: SpT (said)>RT (was, got,etc) $\quad$ RT<

The deictic dualism of speech is observable in this direct speech, in which an entire deictic shift can be seen to take 
place from the current Speaker's domain to the represented Sayer's deictic center.

\section{Tense in Indirect Speech}

According to Declerk [10], the basic choice on introducing a new situation in the unfolding discourse is one between subordination that new situation temporally within an already established temporal domain or shifting the domain to a new one. Tense in complement clauses may be temporally dependent or independent of the main clause. Commonly, the reported situation must precede the communication it self. The past perfect is preferable is such contexts theoretically.

According to the search result in COCA, past perfect in complement clauses is relatively infrequent. Preterite tense in indirect speech, as in Example 3 and 4, enjoys the majority.

In accordance with previous theories of tense, Declerk views tense as a system of temporal deixis locating the situations referred to by clauses in time, taking the ongoing speech exchange as ultimate temporal reference point. Declerck has called this as tense simplification [10]: "it is sometimes possible for the speaker to use a preterit instead of a past perfect or a conditional tense". This criterion used implicitly by Declerck is the possibility of replacing the preterite by a past perfect tense. However, applying this to check examples from the corpus extraction tends to yield results which are rather strained.

1) Example 3

In Bolivia, Morales government initially spent \$25 million to launch BoA in 2009. Vice President Alvaro Garcia said last month that the airline lost \$6 million in its first year, " but in 2010 it stabilized and achieved earnings of more than $\$ 4$ million, aside from the payment of $\$ 34$ million in taxes. " Economy Minister Luis Arce said that between September 2010 and September 2011, the company's earnings totaled about $\$ 90$ million, while its operating costs were about $\$ 78$ million. BoA's success has added to a bitter political feud with Morales opponent Humberto Roca, AeroSur's majority owner. ..

(Source information: INTERNATIONAL NEWS, "Bolivia^s state airline catapults to market leade", by CARLOS VALDEZ, Associated Press in 2012)

In Example 3, the represented state of affairs (totaled about $\$ 90$ million between September 2010 and September 2011 ) was already past in the original speech situation. The simple past tense totaled in the complement clause implicitly indicates a SitT differs from RT, even without the use of the past perfect.

\section{Semantic A Semantic B}

Time Line : SpT (said) $>\mathrm{RT}$ (totaled) $\quad \mathrm{RT}<\mathrm{SitT} \quad \mathrm{Sit}$ $\mathrm{T}<\mathrm{SpT}$

\section{2) Example 4}

Within the past few days, the security forces have descended on Douma, 10 miles from Damascus, to take back neighborhoods they had ceded to armed gunmen. They did the same in Hama, where the bodies of dozens of executed prisoners were found on Thursday. In another sign that the conflict might be escalating, there were unconfirmed reports on Friday of large protests in Aleppo, the country's second largest city and a center of commerce that has stayed largely quiet. Activists said that at least nine protesters were killed when plainclothes security officers attacked the demonstrations. Homs was the site of the worst bloodletting. Activists said at least 40 people, including children, had been killed in sectarian killings and government shelling there since Thursday. ..

(Source information: Section A; Column 0; Foreign Desk; Pg. 1, "Armed Fighters Help Syria Rebels Make Inroads", by KAREEM FAHIM, New York Times in 2012)

The represented state of affairs (at least nine protesters were killed) enjoys anteriority than the original speech situation. Be similar to Example 3, preterite (were) is used instead of expressions of past perfect.

Semantic A SitTSitT $>$ SpT

In the sample of examples extracted from COCA, frequent use of preterite tense in complement clauses in indirect speech shows that past perfect tenses seem to be redundant. A possible reason for this might lie in the point that expressing anteriority over pastness is needless extra job because there are enough contextual clues.

3) Example 5

The sergeant said that two bombers might still be at large, thus the morning lockdown at the ministry and orders to search everyone trying to enter. He said that uniformed soldiers ordinarily walk into the ministry without being searched, an indication of a security weakness the plotters sought to exploit. The Western official said a number of people, including Afghan soldiers, were arrested in connection with the plot on Monday and Tuesday, but the official could not provide an exact figure...

(Source information: Section A; Column 0; Foreign Desk; Pg. 7, "Report of Bombing Plot Sends the Afghan Defense Ministry Into a Near Lockdown", by MATTHEW ROSENBERG and JAWAD SUKHANYAR, New York Times, 2012)

Simple present tense used in this indirect speech is the typical example of blatant violation of traditionally "Backshift" principle in grammar. The speech act by the sergeant is to describe the ordinary situation. The reference time is prior to the speech time. The only possible explanation for this type of tense use is the dependence of context information. It can be inferred in this example that the linguistic effect of being immersive is enhanced with the use of present tense in this situation.

Semantic A Semantic B

Time Line: SpT (said) $<\mathrm{RT}$ (walk) $\quad \mathrm{RT}=\mathrm{SitT} \quad \mathrm{Sit}$ $\mathrm{T}>\mathrm{SpT}$

\section{Tense Use in a Sample of 393 Tokens in Complement Clauses}

To get a first empirically-based idea of the quantitative distribution, we analyze and quantify a sample of 393 sentences with said that extracted from the COCA. The search is executed through the newspaper subcorpora in 
2012 and thus includes examples from American mainstream newspapers. The main quantitative findings of the corpus search are reported in Table I. It shows the distribution of different tenses used in complement clauses in English news texts.

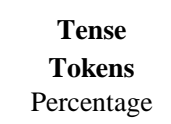

(\%)

Special situations
TABLE I. DISTRIBUTION OF TENSE USE

\begin{tabular}{|c|c|c|c|c|c|}
\hline \multicolumn{6}{|c|}{ DISTRIBUTION OF TENSE USE } \\
\hline \multicolumn{6}{|c|}{ Tense in a sample of 393 said that sentences (data from COCA,2012) } \\
\hline Simple past tense & Past perfect & Present & Present perfect & Simple Future tense & Future in the past \\
\hline 164 & 41 & 86 & 16 & 7 & 27 \\
\hline 41.73 & 10.43 & 21.88 & 4.07 & 1.78 & 6.87 \\
\hline
\end{tabular}

Direct Speech 37 tokens $9.41 \%$
What is immediately striking in these corpus results against the traditionally "Backshift" principle is that past perfect is not as dominant as might have been expected. Only $10.43 \%$ tokens have past perfect tense used in indirect speech, which is the ideal inferences based on traditional syntactic rules. $41.73 \%$ of the tokens in this sample have preterite tense. It enjoys majority over the others. The second most remarkable finding is that more than a quarter of tokens are of present tense, including $21.88 \%$ of tokens with simple present tense and $4.07 \%$ of tokens with present perfect tense. Future tense examples form a minority of about $1.78 \%$, which is less than the examples of tokens with future in the past $(6.87 \%)$. Examples of direct speech $(9.41 \%)$ present us regularly in incomplete or intermittent reported speech when we search with string said that. And data are invalid when there come duplicate sentences. Another occasion is that some that is used as the objective of said in one sentence. Then this sentence is not qualified for this tense research and it is valid.

\section{CONCLUSION}

In this paper, tense interpretation in reported speech is examined. The corpus research is fruitfully employed to gain a better insight in the distribution and functions of tense use in reported speech. The main point is made that tense use and its temporal interpretation are depending heavily on the discourse context of reported speech. The relational value of tense use examples is analyzed in detail in both direct speech and indirect speech to express different relation between Speech Time, Reference Time and Situation Time in reported speech.

In examples of direct speech, tense shifts from the actual speaker's domain to the represented deictic center to refer to actions and states occurring. Then "speaking-now" effect is achieved. Indirect speech, by contrast, is generally assumed to have only one deictic centre-that of the actual speaker. Tense does not need shift from one to another but examples and quantitative analysis certificate tense use in indirect speech largely depends on context clues. The impacts on the interpretation of tenses use in both direct speech and indirect speech relate the speaker's illocutions and propositional contents. And temporal interpretation of tense in reported speech in this research demonstrates that speakers tend to use reported speech to depict represented situation in an actual way.

Further investigation could be developed with a larger corpus and a diachronic approach could be adopted to discuss the change of tense use in reported speech with the advantage and convenience of COCA.

\section{ACKNOWLEDGMENT}

I thank the anonymous reviewers for their perceptive and meticulous comments. All errors and infelicities are, needless to say, my own.

This research is supported by Philosophy and Social Science Fund in Education Department of Jiangsu Province (Project Number: 2013SJD740020

\section{REFERENCES}

[1] R.Declerck, R. Susan, and C. Bert, The Grammar of the English Verb Phrase, vol.1. Berlin: Mouton de Gruyter, 2006, p408.

[2] S.S Carlota, Tense and temporal interpretation, Lingua,2007, p419.

[3] M. Fludernik, Chronology, time, tense and experientiality in narrative. Language and Literature,2003, pp.117-134.

[4] R. W. Langacker, Foundations of Cognitive Grammar,vol.2.Stanford: Standford University Press, 1991.

[5] H. Reichenbach, Elements of Symbolic Logic,London: Macmillan, 1947.

[6] H. Kamp and U. Rohrer, Form discourse to Logic, Dordrecht: Kluwer Academic Publishers, 1993.

[7] B. Rigter, Intensional domains and the use of tense, Journal of Semantics,1982,pp. 95-145.

[8] H.Haberland, Reported speech in Danish, Berlin: Mouton de Gruyter,1986, p.220.

[9] M.A.K.Halliday, An introduction to Functional Grammar, London:Arnold, 1985.

[10] R.Dclearck 1991,Tense inEnglish. Its structure and use in discourse. London:Routledge, 1991. 